\title{
ESTUDO DOS GRANITOS CEARENSES “VERMELHO FILOMENA, MERUOCA CLÁSSICO E VERDE CEARÁ" POR ANÁLISE DIGITAL DE IMAGEM EM CÂMARA COM ATMOSFERA SATURADA EM SO,
}

\author{
Maria de Fátima Bessa Torquato ${ }^{1}$, Joaquim Raul Ferreira Torquato ${ }^{1}$, Carlos Figueiredo ${ }^{2}$, \\ José de Araújo Nogueira Neto ${ }^{3}$
}

\begin{abstract}
RESUMO
No presente trabalho apresentam-se os resultados do ensaio de "envelhecimento acelerado" em três rochas graníticas coletadas no batólito de Meruoca-Rosário na região noroeste do Estado do Ceará. O envelhecimento acelerado foi efetuado numa câmara climática do tipo Fitoclima 300 EDTU, durante 80 ciclos, com temperatura e umidade controladas e sob uma atmosfera constante de $10 \mathrm{ppm}$ de $\mathrm{SO}_{2}$. Imagens obtidas das amostras foram tratadas antes e depois dos processos de envelhecimento por meio do software Visilog 5.1, o qual pode ser usado para estudar qualquer tipo de imagem, quer mineral, quer animal ou vegetal. Nesta aplicação foram escolhidos os parâmetros "cor" e "granulometria" (esta última no sentido de análise de imagem - intervalos de classe). Os resultados obtidos permitiram determinar que, ao longo do envelhecimento acelerado das rochas graníticas escolhidas, ocorreu, em primeiro lugar, como esperado, um forte ataque aos minerais ferromagnesianos, especialmente ao nível iônico. Em todas as amostras a cor das placas rochosas (corpos-de-prova) evoluiu para tonalidades mais amareladas, tendo sido afetados principalmente os minerais do grupo dos feldspatos. Com a continuação do ensaio, ocorreu uma lixiviação dos íons ferrosos e a cor dos corpos de prova retornou praticamente aos parâmetros iniciais. No que diz respeito à "granulometria", todos os tipos de rochas estudadas se comportaram de modo semelhante, mostrando que o maior impacto mediante a ação do ambiente imposto pelo envelhecimento acelerado, se processou logo no início do experimento.
\end{abstract}

Palavras Chaves: Análise de imagem, Rochas ornamentais, Envelhecimento acelerado, Granitos, Batólito de Meruoca

\begin{abstract}
The present work presents the results of the essay "accelerated ageing" in three granite stones collected in the batholite Meruoca-Rosário northwestern region of the state of Ceará. The accelerated ageing was accomplished in a climatic chamber of the kind Fitoclima 300 EDTU, for 80 cycles with controlled temperature and humidity and under a constant atmosphere of $10 \mathrm{ppm}$ of $\mathrm{SO}_{2}$ Images obtained in the samples were treated before and after the ageing processes through the software Visilog 5.1 which can be used to study any kind of image, no matter whether it is mineral vegetal or animal. In this application were chosen the parameters "color" and "granulometry" (the latter in the sense of image analysis-class interval). The results obtained allowed us to determine that throughout the chosen granite stones accelerated ageing, there was, as, as we hoped for, a strong attack to the mafic minerals, especially at the ionic level. In all the samples the color of the rocky plates (test specimen) developed more yellowish tons, having affected mainly the minerals of the feldspar group. With the continuation of the essay, there was the lixiviation of the ferrous ions and the color of the test specimen returned practically to the original parameter. As far as the granulometry is concerned, all the rocks studied present a similar behavior, showing that the biggest impact by means of the action of the environment imposed by the artificial ageing, was processed just at the beginning of the experiment.
\end{abstract}

KEYWORDS: Image analysis; Dimension stones; Accelerated ageing; Granites; Meruoca Batholite.

\section{1 - INTRODUÇÃO}

As técnicas de processamento digital de imagem foram utilizadas pela primeira vez em 1921 para transmissão, a longa distância, de imagens gráficas por cabo submarino que ligava Nova York a Londres (González e Wintz, 1987).

Ao longo dos últimos anos, a análise de imagem vem assumindo um caráter universalista e multidisciplinar, constituindo-se numa técnica de extrema importância cujo objetivo principal é descrever, quantitativamente, imagens de proveniências muito diversificadas, deixando antever a possibilidade de estabelecer correlações entre parâmetros morfológicos e outras propriedades (químicas, físicas, mecânicas, geológicas, biológicas, etc.) dos objetos ou materiais estudados.

Em Geologia, o emprego da técnica é, relativamente, recente e tem maior uso no ramo da Geologia Aplicada, com avanços importantes na exploração de recursos naturais e energéticos, estudos prévios de obras

\footnotetext{
1 - Fundação Núcleo de Tecnologia Industrial do Ceará (NUTEC). Divisão de Materiais. Rua Professor Rômulo Proença s/n. Campus do Pici. 60025-000 - Fortaleza. Ceará. Brasil. torquato@secrel.com.br

2 - Universidade Técnica de Lisboa. Instituto Superior Técnico. Departamento de Engenharia de Minas e Georrecursos Laboratório de Mineralogia e Petrologia. Av. Rovisco Pais. CEP.: 1049-001 - Lisboa. Portugal. nickname@ist.utl.pt 3 - Universidade Federal do Ceará. Departamento de Geologia. Campus do PICI. CEP.: 60455-760 - Fortaleza. Ceará. Brasi nogueira@ufc.br
} 
públicas e, ultimamente, até mesmo, na caracterização litológica.

O presente trabalho mostra os resultados da aplicação desta técnica no estudo de três granitos coletados na Serra da Meruoca/Rosário, na região noroeste do Ceará, envelhecidos artificialmente numa câmara com atmosfera saturada em $\mathrm{SO}_{2}$, simulando os efeitos causados por uma atmosfera industrial em rochas ornamentais.

\section{2 - OS GRANITOS ESTUDADOS}

As áreas onde se localizam as pedreiras destes materiais ornamentais encontram-se situadas no noroeste do Estado do Ceará a cerca de $240 \mathrm{~km}$ de Fortaleza, envolvendo os municípios de Meruoca, Massapê e Alcântaras. Geologicamente, fazem parte do batólito de Meruoca-Rosário. As rochas, comercialmente, são conhecidas como os granitos Vermelho Filomena, Meruoca Clássico e Verde Ceará.

\section{1 - SÍNTESE PETROGRÁFICA}

O granito Vermelho Filomena é uma rocha granítica leucocristalina, de coloração avermelhada e granulação variando de média a grossa onde se podem identificar, facilmente, dois conjuntos de minerais, um félsico formado, fundamentalmente, por quartzo e feldspatos, e outro máfico com predomínio de biotita.

Ao microscópio mostra-se holocristalino inequigranular com cristais anedrais e subedrais, caracterizando a textura hipidiomórfica. É constituído, essencialmente, por feldspato alcalino (55\%), quartzo $(20 \%)$, plagioclásios $(13 \%)$ e biotita $(9 \%)$.

Trata-se de uma rocha ígnea plutônica que pode ser classificada como um Biotita Sienogranito ou Granito 3a (Streckeisen,1976) ou ainda como um Biotita Granito.

O granito Meruoca Clássico é uma rocha leucocrática de coloração cinza esverdeada, apresentando granulação variando de média a grossa, onde se destacam feldspatos, quartzo e minerais máficos (biotita, anfibólios e opacos), textura fanerítica e inequigranular.

Ao microscópio mostra textura inequigranular hipidiomórfica/seriada, com associação mineral formada, essencialmente, por feldspato potássico $(40 \%)$, quartzo (33\%), plagioclásio $(12 \%)$, hornblenda $(7 \%)$ e biotita $(6 \%)$. Como produtos de alteração, foram encontrados clorita, muscovita e minerais argilosos. Os acessórios estão representados por zircão, apatita, titanita, monazita, epidoto e opacos, tendo ainda a presença de fluorita como produto das reações tardimagmáticas.

É uma rocha ígnea plutônica que pode ser classificada como um Biotita Sienogranito, Granito 3a (Streckeisen, 1976) ou Biotita-hornblenda granito.

O granito Verde Ceará se caracteriza por uma coloração verde escura com matizes acinzentadas e castanhas apresentando granulação grossa onde se identificam quartzo, feldspatos, alguns com labradorescência e máficos (biotita e opacos).

Em seções delgadas, este litótipo apresenta características bastante semelhantes às encontradas no granito Meruoca Clássico, sendo, muitas vezes, difícil a distinção entre os dois tipos. Exibe textura inequigranular hipidiomórfica e composição essencial, formada por feldspato potássico (53\%), quartzo $(33 \%)$, plagioclásio $(8 \%)$, biotita e hornblenda $(5 \%)$, e por minerais acessórios do tipo zircão, fluorita, apatita, titanita, alanita, epidoto, minerais argilosos neoformados e opacos.

A composição modal é a de um Biotita Sienogranito ou (Biotita-hornblenda Granito).

\section{3 - ENSAIOS EM CÂMARA COM ATMOSFERA SATURADA EM $\mathrm{SO}_{2}$}

O ensaio descrito neste trabalho é do tipo "envelhecimento acelerado ou artificial", o qual tem como finalidade acelerar, através de técnicas laboratoriais, o processo de envelhecimento de rochas sãs, tendo em vista a avaliação de suas resistências ao intemperismo face aos danos causados pelas variações de temperatura e umidade na presença de uma atmosfera saturada em dióxido de enxofre, simulando regiões industrializadas.

A metodologia utilizada, por não ter similar no Brasil, teve como base o projeto de norma européia prEN BBB 1995.

Durante a execução do trabalho, utilizou-se a Câmara de Ensaios Climáticos (FITOCLIMA 300 EDTU), em funcionamento no Laboratório de Mineralogia e Petrologia do Instituto Superior Técnico de Lisboa (LAMPIST).

Para a realização deste ensaio, preparam-se placas quadradas contendo uma das faces polidas e medindo, aproximadamente, $11 \mathrm{~cm}$ de lado e $2 \mathrm{~cm}$ de espessura.

Inicialmente as amostras foram lavadas com água deionizada e postas para secar em estufa a $70 \pm 5^{\circ} \mathrm{C}$ durante, pelo menos, 72 horas até alcançarem peso constante.

Durante todo o ensaio, o ambiente interno da câmara ficou sujeito a uma atmosfera de 10 ppm de dióxido de enxofre $\left(\mathrm{SO}_{2}\right)$. $\mathrm{O}$ ensaio foi efetuado num total de 80 ciclos com observações visuais das amostras em intervalos de 20 ciclos e com registro de imagens das placas polidas e leitura das massas dos corpos-de-prova a cada 40 ciclos. No fim do ensaio, os corpos-de-prova foram, novamente, secos e pesados para a obtenção do peso final. A norma, ainda, indica que os resultados sejam apresentados sob a forma do percentual de perda de massa.

A programação utilizada na câmara, durante a realização do ensaio, foi a seguinte:

1 hora para estabilizar a temperatura de $60 \pm 5^{\circ} \mathrm{C}$ e umidade relativa de $30 \pm 5 \%$;

6 horas em temperatura de $60 \pm 5^{\circ} \mathrm{C}$ e umidade 
relativa de $30 \pm 5 \%$;

30 minutos para nova estabilização na temperatura de $25 \pm 5^{\circ} \mathrm{C}$ e na umidade relativa de $95 \pm 5 \%$;

6 horas em temperatura de $25 \pm 5^{\circ} \mathrm{C}$ e umidade relativa de $95 \pm 5 \%$.

\section{4 - RESULTADOS E DISCUSSÕES}

\section{1 - Perda de massa}

No final do ensaio ( 80 ciclos) de envelhecimento acelerado, foram calculados os percentuais de perda de massa das amostras das rochas. O granito Vermelho Filomena perdeu, em média, $0,85 \%$; o Meruoca Clássico, $0,15 \%$ e o Verde Ceará, $0,11 \%$.

Através da observação destes valores é possível constatar-se que, de um modo geral, essas perdas são muito diminutas, possivelmente associadas aos minerais máficos. Contudo, embora os percentuais de máficos sejam semelhantes em todas as amostras, verifica-se que o granito Verde Ceará é a rocha que se mostrou mais resistente à perda de massa, sendo seguida pelo Meruoca Clássico e pelo Vermelho Filomena. A porosidade aberta dessas rochas poderá ser um outro fator que influencia essa perda de massa pois, o Vermelho Filomena apresenta 0,965\%, o Meruoca Clássico 0,97 \% e Verde Ceará 0,69\%.

\section{2 - Aquisição das imagens}

Neste trabalho, esta fase se constituiu na aquisição de imagens por scanner de alta resolução, a partir das superfícies polidas das placas quadradas das amostras dos granitos estudados, quer nos seus estados iniciais quer no final de cada etapa de envelhecimento acelerado (40 e 80 ciclos).

Ressalta-se, no entanto, que a aquisição dessas imagens depende de dois fatores, os quais se encontram relacionados com as resoluções espectrais e espaciais que se desejam obter. A resolução espectral se relaciona com os parâmetros de regulação do sistema de aquisição (brilho e contraste), enquanto a resolução espacial está relacionada com a escala de trabalho e depende da resolução espacial máxima permitida pelo equipamento.

No presente trabalho, utilizou-se, para as análises das imagens digitais a cores, o espaço RGB com 2424 x 2362 pixels, as quais foram trabalhadas pelo programa de processamento digital Visilog 5.1, disponível no LAMPIST (IST-Lisboa). Um resumo dos fundamentos matemáticos do estudo deste software está descrito em Bessa-Torquato (2004) e em Bessa-Torquato, Figueiredo e Torquato (2007). Por meio do módulo de análise deste software, tornou-se possível a obtenção de informações numéricas (parâmetros estatísticos) e gráficas (curvas), relacionadas com as intensidades luminosas das imagens.

A partir dos valores quantitativos determinados, procurou-se avaliar, através de medidas associadas e aplicadas às imagens em níveis de cinzento, as alterações sofridas por estas rochas sob o ponto de vista visual (cor) e sua distribuição espacial (granulometria).

Quando se fala do termo "granulometria" em Análise de Imagem, trata-se de uma morfologia matemática, usada em qualquer ramo das ciências, baseada em histogramas de níveis de cinzento que delimitam espaços reais (intervalos de classe), com o mesmo padrão de tons cinza, os quais formam áreas que podem ser interpretadas como granulações independentes. Deste modo, nenhuma semelhança existe com o termo "granulometria" usado em Geologia quando se trata do tamanho de grãos minerais.

Relativamente às informações gráficas, obtiveramse curvas de distribuição de freqüência dos níveis de cinzento e curvas de distribuição de tamanho (granulometria ou intervalos de classe) sob o ponto de vista matemático dos elementos de textura das imagens estudadas. Como parâmetros estatísticos foram calculadas as médias, a moda, os desvios padrões, máximos e mínimos.

\section{3 - Análise de imagem}

A textura de uma imagem, em níveis de cinzento, pode ser admitida como sendo composta pelos vários elementos de textura, assim como o arranjo e a distribuição espacial definem o seu tipo (Tomita et al.,1990 in: Figueiredo, 1999).

As alterações impostas sob certas condições a que podem ser submetidos os materiais rochosos podem modificar, de modo intenso, a textura dos mesmos, transformando o arranjo estrutural (dispersão) e as propriedades (cor, forma, ordem, etc.) das suas unidades estruturais elementares (elementos de textura), principalmente, pela formação de heterogeneidades de natureza variada como vazios, alterações, etc. (Figueiredo, Maurício e Aires-Barros, 1995, 1996).

Dentre os vários aspectos passíveis de serem estudados com o auxílio da técnica de análise de imagem, neste trabalho, optou-se por avaliar os aspectos físicos de cor e granulometria, a partir de imagens adquiridas através da digitalização de superfícies polidas de placas das rochas estudadas nas diferentes fases do experimento.

A avaliação da cor foi, neste caso, efetivada com o auxílio dos histogramas de intensidade individuais de cada uma das suas componentes (no espaço RGB) e dos respectivos parâmetros estatísticos básicos, média, moda, desvio padrão e valores extremos (máximos e mínimos).

Para a avaliação do tamanho e arranjo espacial dos elementos de imagem em níveis de cinzento, foram realizadas análises granulométricas por aberturas e fechos de tamanho crescente (operações básicas da Morfologia Matemática).

Para se estudar as alterações do ponto de vista granulométrico, as imagens originais foram convertidas do seu espaço RGB para o espaço ITS (Intensidade, 
Tinta e Saturação), sendo depois utilizada somente a sua componente I (Intensidade).

A etapa zero (0) do experimento corresponde às imagens das rochas "in natura", a etapa 1 refere-se às imagens dessas placas capturadas após 40 ciclos e a etapa 2 representa as imagens obtidas após os 80 ciclos de exposição sob as condições impostas pela câmara.

\subsection{1 - Cor}

Relativamente à cor, os parâmetros estatísticos já mencionados, obtidos no espaço RGB (vermelho, verde e azul) encontram-se discriminados na Tabela 1 e mostram-se semelhantes quando comparados usando o "desvio padrão". Os valores individuais podem ser observados nas Figuras 1 a 3 que mostram os histogramas dos níveis de cinzento dos tipos litológicos em estudo, com suas respectivas imagens captadas nas diferentes fases do experimento.

Conforme pode ser observado, quer nos gráficos, quer nas imagens, o aspecto global das amostras indica que as superfícies polidas das placas dos granitos tornaram-se mais claras e com tonalidades amareladas logo na primeira fase do ensaio (40 ciclos). Contudo, após a segunda fase do ensaio ( 80 ciclos), o efeito de clareamento ainda se encontra levemente elevado, porém sem a tonalidade amarelada que se verifica na primeira fase.

A alteração colorimétrica destas rochas é evidente pela análise visual das imagens e reforçada pelas curvas individuais de cada componente de cor no espaço RGB, as quais são unimodais, com leves deslocamentos para os valores mais altos dos níveis de cinzento.

Em relação ao granito Vermelho Filomena, os parâmetros estatísticos evidenciam alterações de luminosidade para mais claro, principalmente, na primeira etapa do envelhecimento acelerado. Nesta fase, tanto a média como a moda e a dispersão são mais elevadas em todos os canais (vermelho, verde e azul), quando comparadas com a rocha "in natura", e os valores dos mínimos se alargam. A etapa 2 do experimento mostrou um ligeiro aumento dos valores referentes à média determinada no canal azul e uma leve diminuição dos valores atribuídos a este parâmetro nos canais verde e vermelho em relação à etapa 1 . No entanto, quando comparados com os valores obtidos na rocha sã, constata-se um leve aumento de todos os parâmetros estatísticos básicos demonstrando, assim, também, um leve clareamento desse material nesta fase em relação à fase inicial (Figura 1).

Os granitos Meruoca Clássico e Verde Ceará também apresentam dados estatísticos que demonstram um leve clareamento nas suas tonalidades básicas, sob a ação das condições impostas pelo envelhecimento acelerado na presença de uma atmosfera rica em $\mathrm{SO}_{2}$. As curvas dos níveis de cinzento nos canais RGB mostram deslocamentos para níveis mais elevados em todas as etapas do ensaio quando comparadas com a etapa zero (rocha in natura), evidenciando, desta forma, as leves mudanças de tonalidade que se visualizam diretamente das imagens. Essas variações podem ser percebidas, mais nitidamente, pela observação dos histogramas dos níveis de cinzento comparativos dos canais individuais de cores nas diferentes etapas do experimento (Figuras 2 e 3 ).

De um modo geral, quando se analisam os granitos conjuntamente, torna-se possível afirmar que ocorreram alterações de luminosidade nos níveis de cinzento mais elevados, tanto na primeira como na segunda fase do ensaio, especialmente, nos canais vermelho e verde.

Tabela 1 - Dados estatísticos básicos dos granitos Vermelho Filomena (V F), Meruoca Clássico (M C) e Verde Ceará (V C) obtidos em câmara climática através da análise de imagem da amostra sã (etapa 0), após 40 ciclos (etapa 1) e depois de 80 ciclos (etapa 2).

\begin{tabular}{|c|c|c|c|c|c|c|c|c|c|c|}
\hline \multirow{3}{*}{ Rocha } & \multirow{3}{*}{ Valor } & \multicolumn{3}{|c|}{ ETAPA 0} & \multicolumn{3}{|c|}{ ETAPA 1} & \multicolumn{3}{|c|}{ ETAPA 2} \\
\hline & & \multicolumn{3}{|c|}{ Canai: } & \multicolumn{3}{|c|}{ Canai! } & \multicolumn{3}{|c|}{ Canai! } \\
\hline & & $\mathrm{R}$ & $G$ & $B$ & $\mathrm{R}$ & $G$ & $B$ & $\mathrm{R}$ & $G$ & B \\
\hline \multirow{5}{*}{ VF } & Média & 187,64 & 151,18 & 141,96 & 201,48 & 163,86 & 142,26 & 200,74 & 160,84 & 153,71 \\
\hline & Máxim• & 255 & 255 & 254 & 255 & 255 & 253 & 2555 & 255 & 255 \\
\hline & Mínim• & 2 & 1 & 6 & 1 & 0 & 2 & 0 & 0 & 4 \\
\hline & Moda & 212 & 161 & 148 & 253 & 182 & 153 & 253 & 179 & 163 \\
\hline & Dv.Pad & 38,88 & 29,69 & 27,16 & 43,42 & 33,72 & 29,18 & 44,83 & 31,29 & 30,69 \\
\hline \multirow{5}{*}{ MC } & Média & 179,55 & $\overline{178,61}$ & 179,96 & 191,64 & 189,90 & 179,28 & 189,36 & $\overline{185,41}$ & 190,29 \\
\hline & Máxim• & 254 & 255 & 255 & 255 & 255 & 254 & 255 & 255 & 255 \\
\hline & Mínim• & 0 & 0 & 3 & 0 & 0 & 0 & 0 & 0 & 1 \\
\hline & Moda & 199 & 200 & 202 & 222 & 222 & 203 & 221 & 212 & 217 \\
\hline & Dv.Pad & 41,82 & 42,39 & 39,91 & 44,76 & 44,90 & 42,27 & 48,20 & 47,63 & 44,80 \\
\hline \multirow{5}{*}{ VC } & Média & 120,33 & 122,17 & 119,88 & 132,01 & 132,81 & 117,94 & 133,39 & 133,58 & 131,92 \\
\hline & Máxim• & 255 & 255 & 255 & 255 & 255 & 255 & 255 & 255 & 255 \\
\hline & Mínim• & 0 & 0 & 8 & 0 & 0 & 0 & 0 & 0 & 8 \\
\hline & Moda & 126 & 132 & 90 & 143 & 140 & 87 & 142 & 141 & 101 \\
\hline & Dv. Pad & 35,63 & 36,66 & 35,64 & 39,17 & 39,99 & 38,85 & 40,07 & 39,61 & 39,14 \\
\hline
\end{tabular}

(R) Red (vermelho); (G) Green (verde); (B) Blue (azul) 

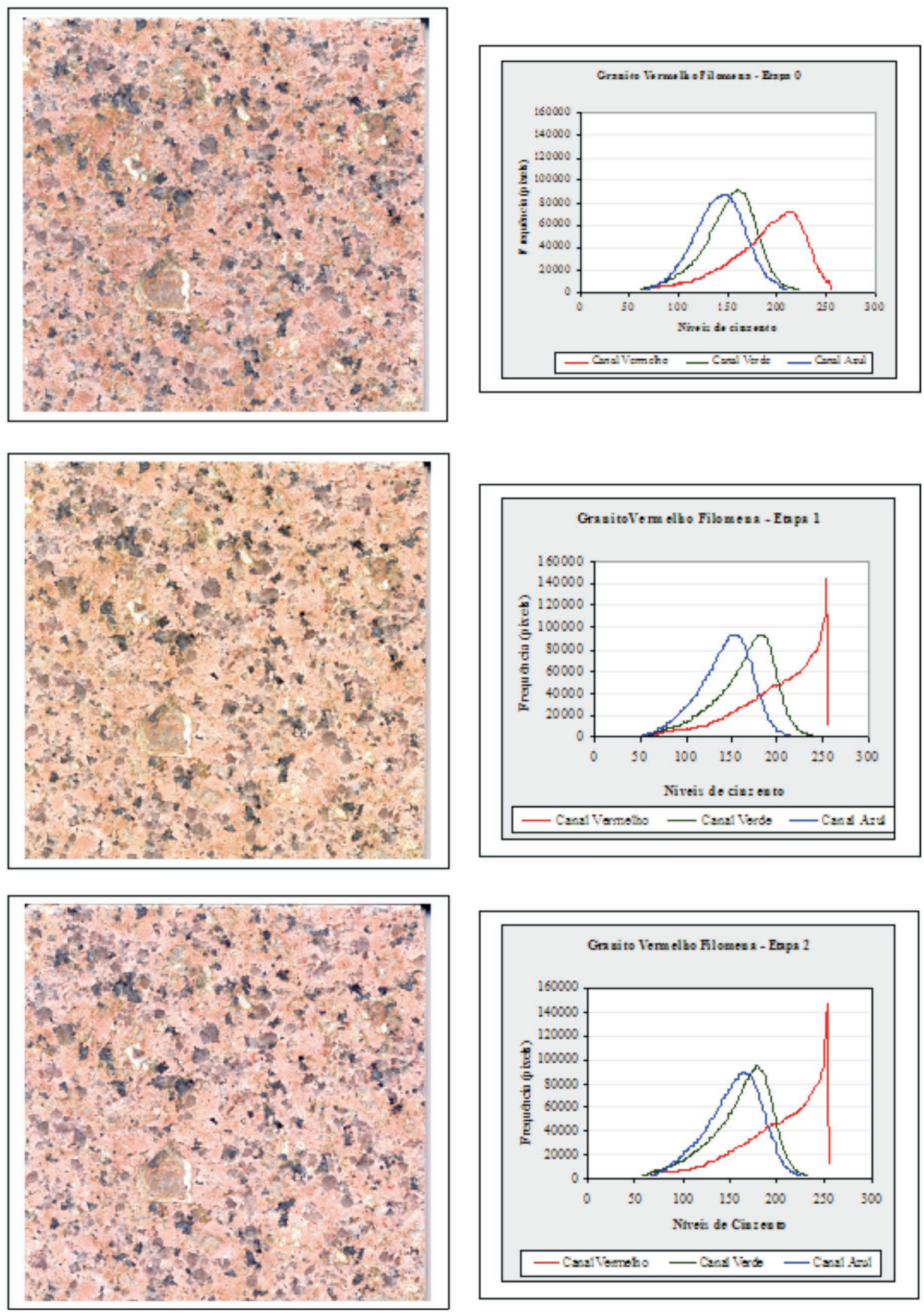

Figura 1 - Granito Vermelho Filomena. Imagens das placas e histogramas individuais de cor para as componentes vermelha $(R)$, verde $(G)$ e azul $(B)$ nas diferentes etapas de envelhecimento. A terminação da curva de modo abrupto mostra exclusivamente ruído eletrônicos. Etapa 0: rocha sã, etapa 1: após 40 ciclos e etapa 2: após 80 ciclos. Conforme o indicado no texto, as placas têm $11 \mathrm{~cm}$ de lado. 

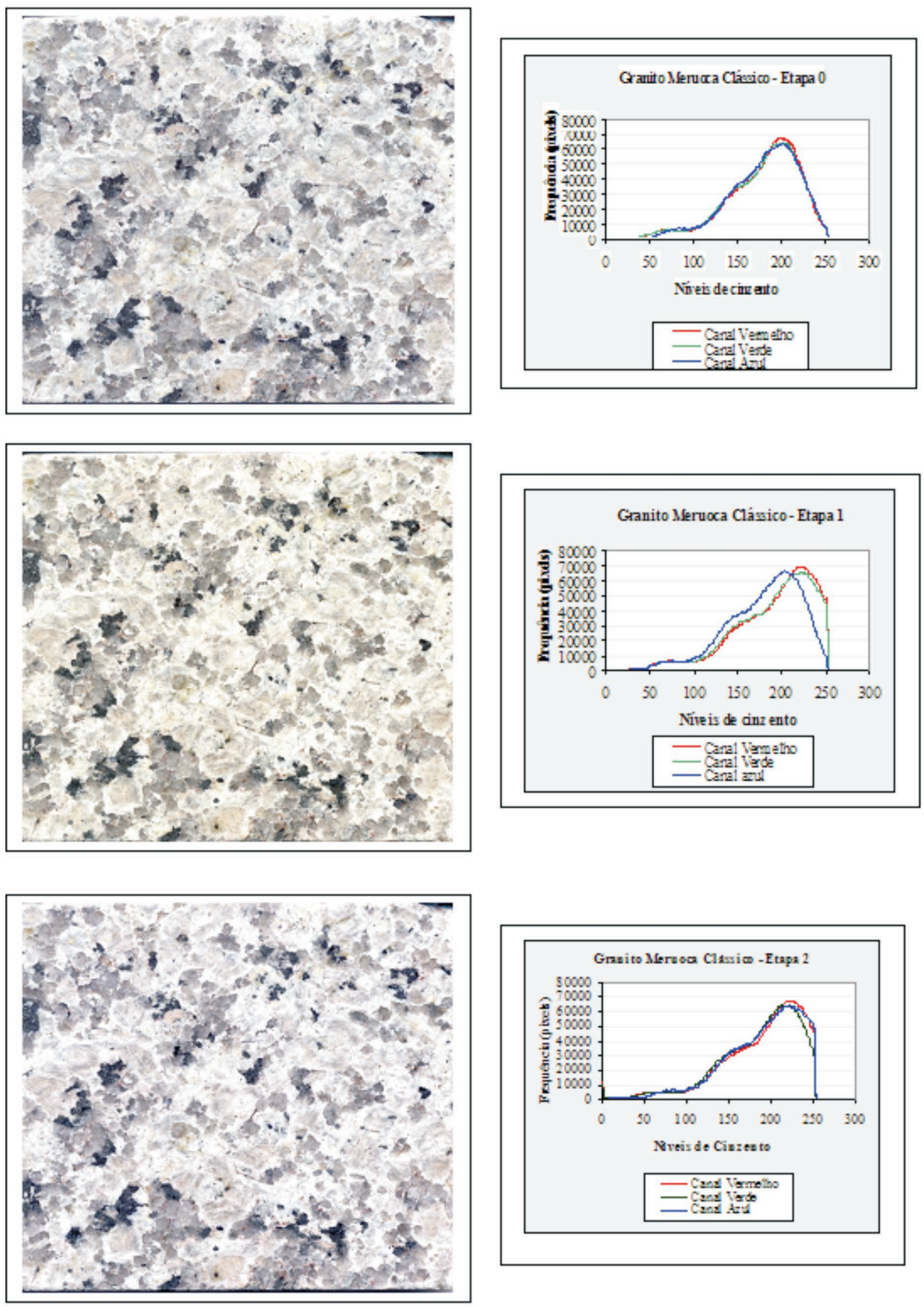

Figura 2 - Granito Meruoca Clássico. Imagens das placas e histogramas individuais de cor para as componentes vermelha $(R)$, verde $(G)$ e azul $(B)$ nas diferentes etapas de envelhecimento. Etapa 0: rocha sã, etapa 1: após 40 ciclos e etapa 2: após 80 ciclos. Conforme o indicado no texto, as placas têm $11 \mathrm{~cm}$ de lado. 

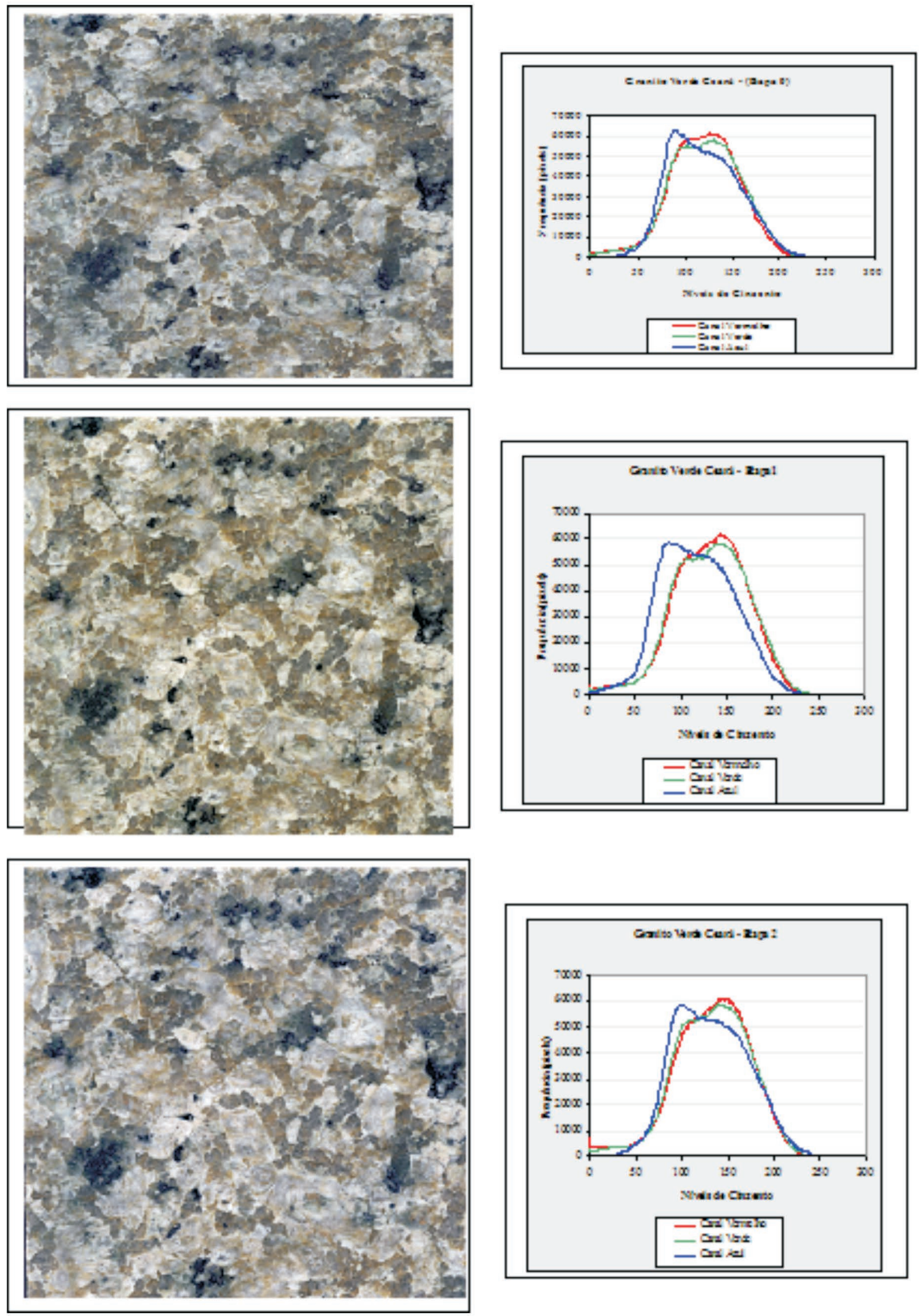

Figura 3 - Granito Verde Ceará. Imagens das placas e histogramas individuais de cor para as componentes vermelha $(R)$, verde $(G)$ e azul $(B)$ nas diferentes etapas de envelhecimento. Etapa 0: rocha sã etapa 1: após 40 ciclos e etapa 2: após 80 ciclos. Conforme o indicado no texto, as placas têm $11 \mathrm{~cm}$ de lado. 
Ressalte-se que, nesta fase do experimento, os dados estatísticos mostram uma tendência do canal azul permanecer quase constante nos granitos Vermelho Filomena e Meruoca Clássico.

$\mathrm{O}$ ácido sulfúrico $\left(\mathrm{H}_{2} \mathrm{SO}_{4}\right)$, produzido no interior da câmara climática, afeta os minerais das amostras, especialmente, os ferromagnesianos, onde ataca, principalmente, o ferro. A solução ácida que contém este elemento provoca o manchamento dos minerais mais claros, como os feldspatos superficiais que passam a exibir uma coloração castanho-amarelada. A continuação desse processo (etapa 2) induz a uma lixiviação das substâncias químicas, as quais são carreadas per descensu, por capilaridade para as superfícies inferiores das amostras onde se depositam formando concentrações escuras ferruginosas.

\subsubsection{Granulometria}

As curvas de distribuição granulométrica por abertura (a) e fecho (b) das imagens, em níveis de cinzento, obtidas nas diferentes etapas do ensaio, estão mostradas na Figura 4. Notar que, em cada fase de cada rocha, as curvas se mantêm quase sobrepostas.

A aplicação às imagens de aberturas e fechos de tamanho crescente, obtidas a partir das amostras sãs (etapa 0) e alteradas (etapas 1 e 2), mostra algumas diferenças na distribuição do tamanho dos elementos de textura nas imagens em níveis de cinzento, especialmente, em nível das classes de menores dimensões, representadas tanto na fase clara como na fase escura. Contudo, as diferenças observadas, ao longo do ensaio, nas curvas granulométricas das estruturas mais claras, são bem distintas das verificadas para as curvas das estruturas representadas pela fase escura.

De um modo geral, quando se comparam as curvas de distribuição granulométrica que representam as fases claras e escuras em todas as rochas, verifica-se que os aumentos na freqüência das classes de menor tamanho $(0-2 \mathrm{~mm})$ são mais expressivos nas curvas da fase escura (Figura 4). Tal fato indica o ataque preferencial aos minerais ferromagnesianos, embora as pequenas variações exibidas em todas as curvas das fases claras indiquem que os minerais claros também são ligeiramente afetados.

Para as estruturas representadas na fase escura, as alterações sofridas pelas rochas, ao longo do ensaio, se manifestam, sobretudo, com o aumento da freqüência com dimensões entre 0 e $2 \mathrm{~mm}$, com particular relevo para a classe de tamanho $0-1 \mathrm{~mm}$, à custa dos elementos de maior dimensão existentes, inicialmente, nas rochas. Esse fato vem demonstrar que os elementos texturais representados na fase escura se tornam cada vez mais finos e granulometricamente mais homogêneos (calibrados) ao longo do experimento, apresentando, em média, uma granularidade mais fina e uma menor dispersão de tamanhos nas etapas finais do ensaio de envelhecimento.
Pela análise comparativa das imagens em cor real e em falsa cor (Figuras 5 a 7) das amostras iniciais (sãs) e após a última etapa do envelhecimento (etapa 2), constata-se o aparecimento de elementos com textura de menores dimensões na fase escura, dando origem, para essa fase, a uma textura mais fina. Esse aspecto é mais facilmente visualizado nas imagens apresentadas em falsa cor (Figuras 5, 6 e 7- $c$ e $d$ ) em todas as rochas analisadas.

Relativamente às estruturas representadas na fase clara (Figura 4, Vermelho Filomena e Verde Ceará (a)), o ensaio efetuado parece dar lugar a uma textura, em média, mais grossa e heterogênea (mal calibrada), na medida em que se intensifica o processo de envelhecimento. Os valores dos parâmetros estatísticos básicos (média e desvio-padrão), que caracterizam as curvas de distribuição granulométrica obtidas para os elementos mais claros da textura, aumentam à medida que evolui o processo de envelhecimento. Para essa fase, parece ser possível observar, sobretudo, um deslocamento das curvas granulométricas, obtidas nas etapas 1 e 2 , no sentido do aumento da freqüência das classes de tamanho, de ordem e de grandeza imediatamente superior às existentes na etapa inicial (etapa 0). Tal fato poderá estar associado ao aparecimento de elementos claros de textura de maiores dimensões, especialmente, à custa dos elementos de menores dimensões, existentes inicialmente na rocha. A textura, assim, resultante será, em média, mais grossa do que a inicial, à medida em que o envelhecimento acelerado se intensifica.

As observações das imagens obtidas em cor real (Figuras 5, 6 e 7 - $a$ e $b$ ) de todas as amostras dos granitos, em questão, na etapa zero (rochas sãs) e na etapa final do envelhecimento (etapa 2) permite constatar uma perda de nitidez das descontinuidades estruturais existentes e detectadas nas imagens iniciais (etapa 0) com o ensaio de envelhecimento, dando lugar a contornos difusos (quer em minerais quer em microfraturas e traços de clivagem), bem como o clareamento global da amostra e a diminuição do contraste desses elementos estruturais.

Tal fato permite evidenciar que, neste caso, o processo de alteração dessas rochas atua, ao longo do ensaio de envelhecimento, de maneira mais eficaz em nível das descontinuidades estruturais, com dimensões inferiores às da granulação das rochas estudadas, podendo, portanto, corresponder, sobretudo, a descontinuidades cristalográficas (químicas e estruturais) intragranulares.

Atendendo que a informação obtida por aberturas de tamanho crescente da fase clara (máximos regionais e locais da imagem) pode estar associada, principalmente, aos componentes mineralógicos mais claros (como, por exemplo, aos feldspatos) das rochas estudadas e, ainda, que a informação granulométrica sobre a fase escura (mínimos regionais e locais da imagem), obtida por fechos de tamanho crescente, pode ser admitida como representativa, sobretudo, do comportamento 

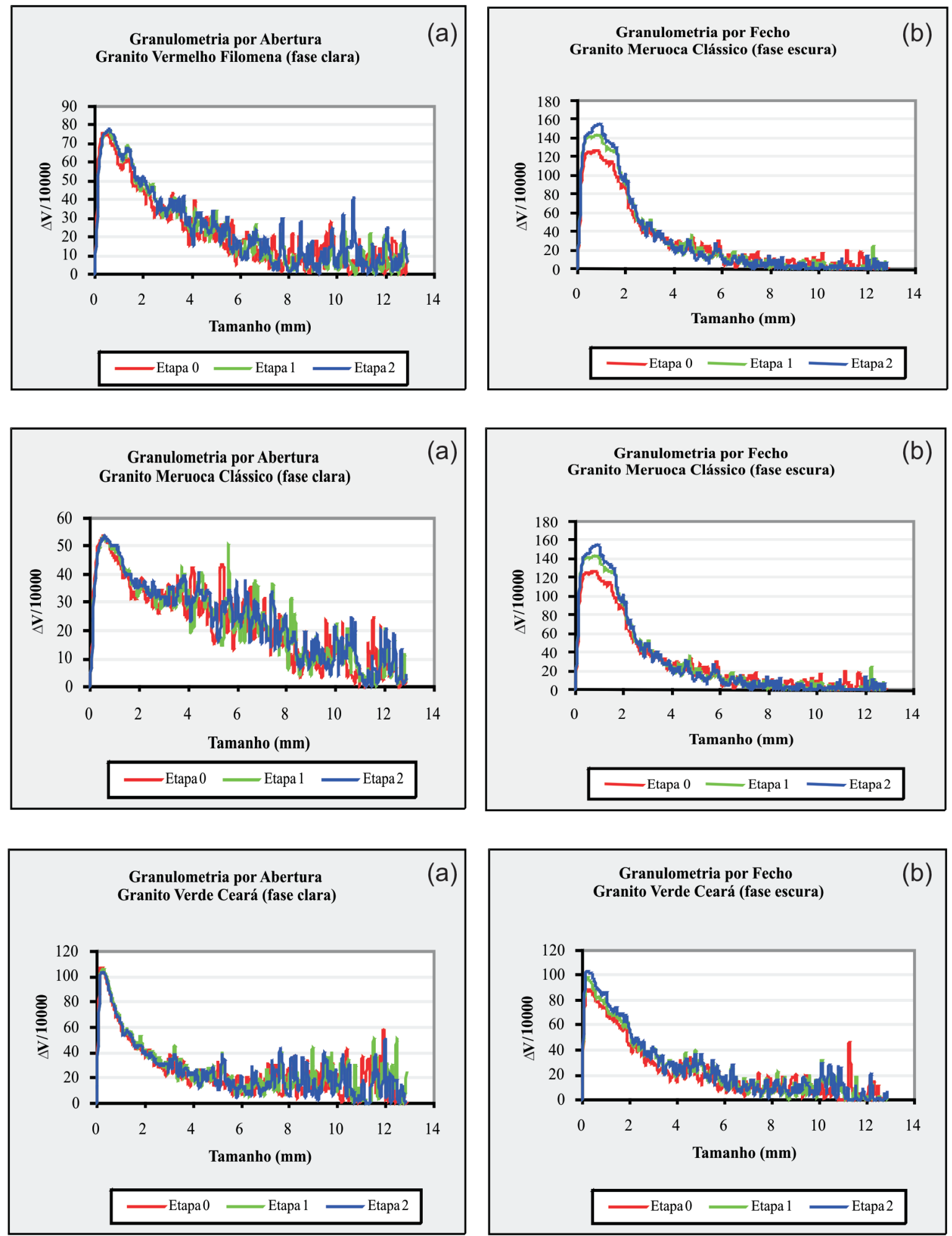

Figura 4 - Curvas de distribuição granulométrica por abertura (a) e fecho (b) das imagens, em níveis de cinzento, obtidas nas diferentes etapas do ensaio. Notar que, em cada fase de cada rocha, os valores se mantém quase constantes.

dos minerais escuros, quais sejam, os opacos e os ferromagnesianos, torna-se possível deduzir que, nas condições impostas pelo processo de alteração a que foram submetidos esses materiais, as maiores alterações se processam nos minerais escuros, embora todos os demais minerais das rochas estejam envolvidas no processo.

\section{5 - CONCLUSÕES}

Os diagramas e imagens apresentados evidenciam o maior envolvimento no processo de alteração dos elementos estruturais/texturais das rochas representadas na fase escura das imagens em níveis de cinzento, corroborando, assim, a hipótese colocada de que os 

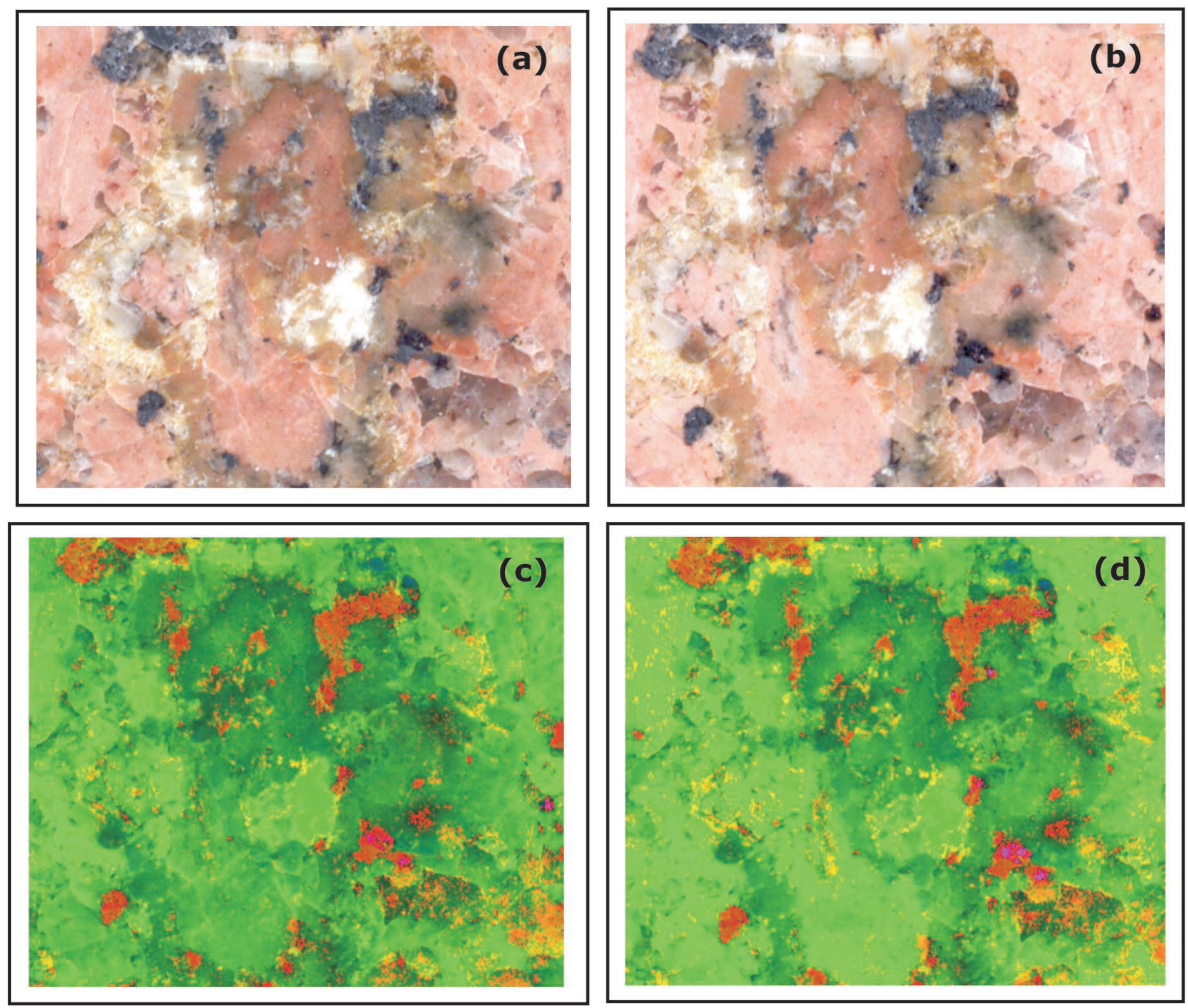

Figura 5 - Granito Vermelho Filomena. Pormenor em cor real (a,b) e em falsa cor (c,d) da superfície polida da amostra antes $(a, c)$ e após (b,d) o envelhecimento. Ampliação aproximada de 5,2 vezes.
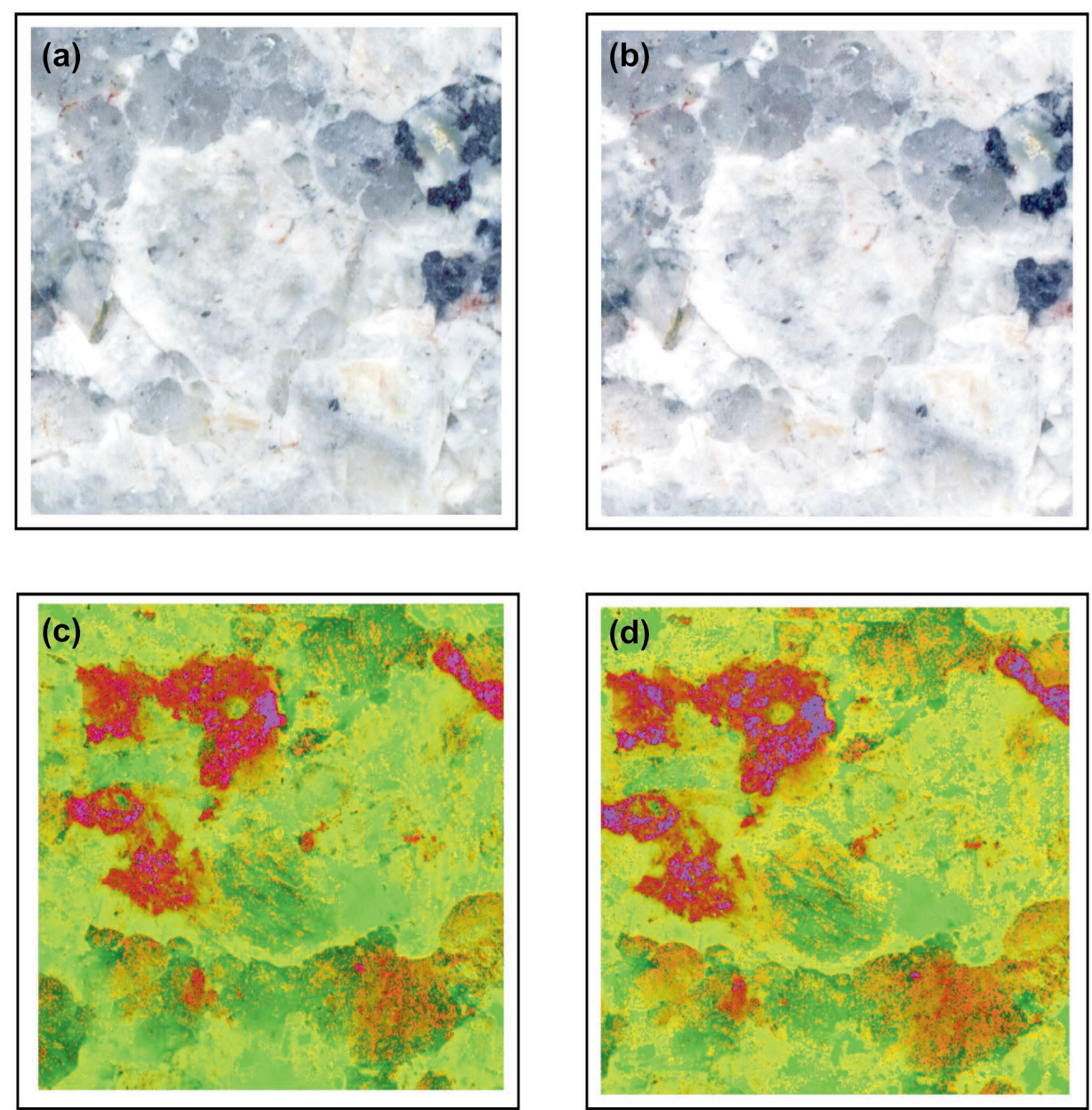

Figura 6-Granito Meruoca Clássico. Pormenor em cor real (a,b) e em falsa cor (c,d) da superficie polida da amostra antes (a,c) e após $(b, d)$ o envelhecimento. Ampliação aproximada de 5,2 vezes. 

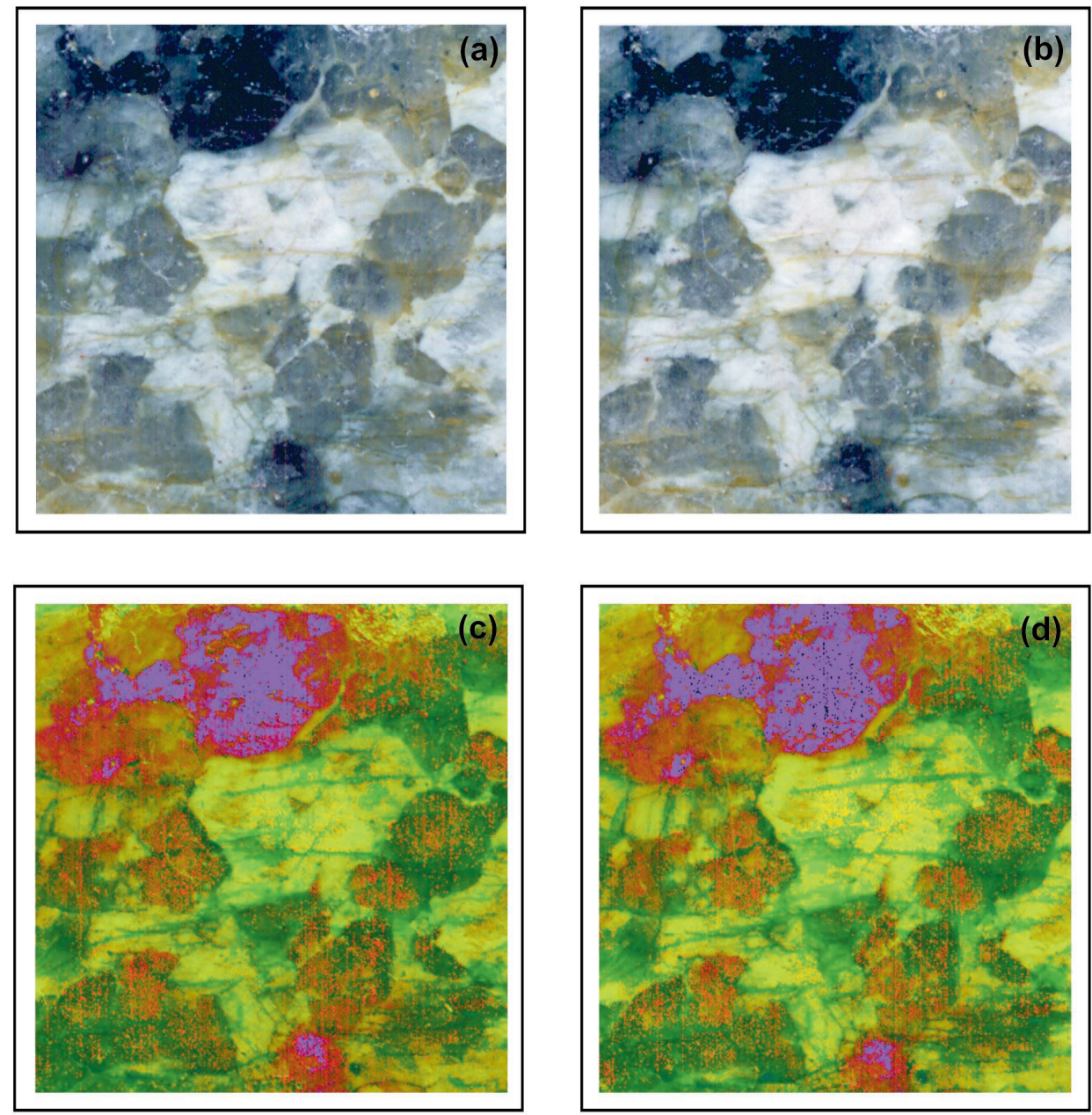

Figura 7 - Granito Verde Ceará. Pormenor em cor real $(a, b)$ e em falsa cor $(c, d)$ da superfície polida da amostra antes $(a, c)$ e após $(b, d)$ o envelhecimento. Ampliação aproximada de 5,2 vezes.

minerais ferromagnesianos e/ou os óxidos e hidróxidos de ferro são os constituintes mineralógicos que mais contribuem neste processo e que as reações químicas se desenvolvem, sobretudo, em nível iônico.

Essas alterações que se manifestam mais evidentemente como um aumento gradual das freqüências em determinadas classes granulométricas, nas variações dos respectivos parâmetros estatísticos, no esbatimento dos contrastes dos elementos de imagem e, ainda, no clareamento global das amostras não são, todavia, facilmente observáveis pela simples análise visual das superfícies de amostras de rochas polidas ao longo do experimento.

Esse fato constitui, de certo modo, uma vantagem, para esse tipo de análise, uma vez que põe em evidência modificações que se processam através de reações químicas que se passam principalmente no nível iônico das rochas e que, embora se manifestem de uma maneira muito sutil, são importantes para a vida útil desses materiais nos seus diversos campos de aplicações, uma vez que a continuação do processo poderá causar danos irreversíveis aos materiais derivados e, conseqüentemente, às obras de engenharia onde estão ou possam vir a ser aplicados.

Ressalta-se, assim, portanto, a importância de se levar em consideração, além das características tecnológicas destes materiais, as características do ambiente onde estão ou serão inseridas as construções, nas quais estão ou passarão a fazer parte integrante.

A semelhança do que ocorre relativamente à cor, também no que concerne à granulometria, todos os tipos de rochas estudados apresentam comportamentos semelhantes, cujas curvas granulométricas mostram que o maior impacto mediante a ação do ambiente imposto pelo envelhecimento acelerado acontece logo na primeira fase do experimento.

\section{6 - REFERÊNCIAS BIBLIOGRAFICAS}

Bessa-Torquato, M. de F. Rochas ornamentais do Nordeste do Ceará (Brasil). Propriedades tecnológicas, Alteração e Alterabilidade dos granitos Vermelho Filomena, Meruoca Clássico e Verde Ceará. 2004. Tese (Doutorado). Instituto Superior Técnico. Lisboa. 274p.

Bessa-Torquato, M. de F., Figueiredo, C., Torquato, J.R.F. Utilização da metodologia "Análise de Imagem" no estudo de rochas ornamentais. 2007. Revista de Geologia. UFC. Departamento de Geologia, v.20 (1) 65-81

Figueiredo, C. Alteração, Alterabilidade e patrimônio cultural construído: o caso da Basílica da Estrela. 1999. Tese (Doutorado). Instituto superior Técnico. Lisboa, $321 \mathrm{pp}$.

Figueiredo, C.; Maurício, A. Aires-Barros, L. Morphological analysis and quantification of rock weathered surfaces: preliminary study, 1995. Memória, Porto, v.4 p.183-188.

Figueiredo, C.; Maurício, A. Aires-Barros, L. Grey Tone Function 
covariance applied to the analysis and quantification of rock decayed surfaces: a preliminary study. 1996. In: $8^{\text {th }}$ Portuguese Conference On Pattern Recognition, Recpad 96, Guimarães, Portugal, p. 237-241.

González, R.C. e Wintz, P. Digital image processing. Addison Wesley. $2^{\text {nd }}$. ed. 1987. Reading, Massachussetts, $503 \mathrm{pp}$
Mertz, J.D. Structures de porosité et proprietés de transport dans lês grés.Sci. 1991. Geol. Mém., Strasburg. 90, 149 pp.

prEN BBB 1995. Methods of test for natural stone, part XI: Acceleration decay test by temperature, humidity, and sulfur dioxide. CEN.

Streckeisen, A. L. To each plutonic rock its proper name. 1976. Earth Science reviews, v.12. p.1-33. 